\title{
Molecular Interactions of L-Histidine in an Aqueous Buffer Solution in the Temperature Range of 288-313 K
}

\author{
E. Yu. Tyunina ${ }^{a, *}$, V. G. Badelin ${ }^{a}$, and A. A. Kuritsyna ${ }^{b}$ \\ ${ }^{a}$ Krestov Institute of Solution Chemistry, Russian Academy of Sciences, Ivanovo, 153045 Russia \\ ${ }^{b}$ Ivanovo State University of Chemistry and Technology, Ivanovo, 153000 Russia \\ *e-mail: tey@isc-ras.ru \\ Received May 23, 2019; revised September 17, 2019; accepted September 20, 2019
}

\begin{abstract}
The behavior of L-histidine (His) in an aqueous buffer solution ( $\mathrm{pH} 7.4$ ) is studied via densimetry and differential scanning calorimetry. The densities and specific heat capacities of solutions of the amino acid are determined in the $288.15-313.15 \mathrm{~K}$ range of temperatures at His concentrations of 0.00215 to $0.03648 \mathrm{~mol} \mathrm{~kg}^{-1}$. The apparent and partial molar parameters of L-histidine in the buffer solution are found, and features of the temperature and concentration dependences are identified. It is shown that the partial molar properties of transferring the amino acid from water to the buffer solution (both volume and heat capacity) have positive values in the investigated range of temperatures. Different types of molecular interaction between the solute and the solvent are considered using the Gurney model.
\end{abstract}

Keywords: density, heat capacity, apparent molar volume, apparent molar heat capacity, L-histidine, buffer solution

DOI: $10.1134 /$ S0036024420040226

\section{INTRODUCTION}

Most biochemical processes occur in aqueous solutions. It is therefore of interest to study the physicochemical properties of biologically active substances in liquid phases [1-6]. Of special importance is the use of buffer systems that produce solutions similar to physiological media [7, 8]. Amino acid residues in plasma proteins can interact with one another, surrounding water molecules, or other components of the solution (e.g., electrolytes and drugs) through nonvalent interactions (hydrogen bonding, $\pi-\pi$ stacking, and electrostatic and van der Waals interactions). It is important to study the thermodynamic properties of amino acids in aqueous buffer solutions in order to understand the molecular bases of the conformational stability and functional activity of proteins.

It is of relevance today to explore the behavior of amino acids, the molecules of which have polar side chains [1, 6, 9-11]. Among these is the heterocyclic amino acid L-histidine, having an imidazole moiety, which can act as both a donor and an acceptor in hydrogen bonding and can react as both an acid and a base, depending on the range of $\mathrm{pH}$. Histidine residues have been identified in the active sites of $\sim 50 \%$ of all protein enzymes $[12,13]$. This amino acid is a precursor in the biosynthesis of histamine and participates in the biosynthesis of proteins during functioning, repair and growth of tissues. Histidine is a component of many dietary supplements marketed as useful in management of eye diseases, rheumatoid arthritis, allergies, ulcers, and anemia [14].

In the literature, there are no data on the density and heat capacity of the system L-histidine-aqueous phosphate buffer solution ( $\mathrm{pH}$ 7.4). The aim of this work was to identify features of the intermolecular interactions of His in an aqueous buffer solution ( $\mathrm{pH}$ 7.4) over a wide range of temperatures and concentrations via densimetry and differential scanning calorimetry.

\section{EXPERIMENTAL}

L-Histidine (Sigma Aldrich, Japan; CAS 63-91-2, $>99 \%$ purity) was used in this work. The amino acid was dried in a vacuum at $343 \mathrm{~K}$ for $48 \mathrm{~h}$ immediately before use. Our studies were performed with aqueous buffer solutions ( $\mathrm{pH}$ 7.4) containing $\mathrm{NaH}_{2} \mathrm{PO}_{4}$ and $\mathrm{Na}_{2} \mathrm{HPO}_{4}$, due to which the medium was similar to real biological systems. The $\mathrm{pH}$ of the solutions were measured with a Mettler Toledo FiveEasy $\mathrm{pH}$ meter. All solutions were prepared by weighing on a Sartorius ME215S high-precision lab balance (accuracy of weighing, $1 \times 10^{-5} \mathrm{~g}$ ). The concentration of the amino acid was varied in the range of $0.00215-0.03648 \mathrm{~mol} \mathrm{~kg}^{-1}$.

The densities of the investigated solutions were measured with a DMA-5000M vibrating tube densimeter (Anton Paar, Austria) at temperatures of 288.15, 298.15, 303.15, 308.15, and 313.15 K. Two 
Table 1. Density $\rho$ of aqueous buffer solutions of L-histidine at different concentrations and temperatures

\begin{tabular}{c|c|c|c|c|c}
\hline$m, \mathrm{~mol} \mathrm{~kg}^{-1}$ & $288.15 \mathrm{~K}$ & $298.15 \mathrm{~K}$ & $303.15 \mathrm{~K}$ & $308.15 \mathrm{~K}$ & $313.15 \mathrm{~K}$ \\
\hline & & \multicolumn{2}{|c|}{$\rho^{\mathrm{a}}, \mathrm{kg} \mathrm{m}^{-3}$} & 1023.023 & 1021.012 \\
0 & 1029.289 & 1026.562 & 1024.859 & 1023.129 & 1021.115 \\
0.0022 & 1029.406 & 1026.674 & 1024.969 & 1023.357 & 1021.329 \\
0.0104 & 1029.658 & 1026.922 & 1025.209 & 1023.489 & 1021.462 \\
0.0125 & 1029.810 & 1027.064 & 1025.339 & 1023.565 & 1021.539 \\
0.0177 & 1029.890 & 1027.141 & 1025.424 & 1023.749 & 1021.726 \\
0.0198 & 1030.096 & 1027.332 & 1025.604 & 1023.807 & 1021.794 \\
0.0219 & 1030.153 & 1027.409 & 1025.676 & 1023.878 & 1021.854 \\
0.0249 & 1030.231 & 1027.486 & 1025.739 & 1023.977 & 1021.934 \\
0.0320 & 1030.331 & 1027.582 & 1025.830 & 1024.185 & 1022.140 \\
0.0364 & 1030.570 & 1027.817 & 1026.054 & 1024.295 & 1022.254 \\
\hline
\end{tabular}

${ }^{\text {a }}$ Error in the experimental values of $\rho$ is $\pm 3 \times 10^{-3} \mathrm{~kg} \mathrm{~m}^{-3}$.

Table 2. Specific heat capacity $C_{p}$ of aqueous buffer solutions of L-histidine at different concentrations and temperatures

\begin{tabular}{c|c|c|c|c|c|c}
\hline$m, \mathrm{~mol} \mathrm{~kg}^{-1}$ & $288.15 \mathrm{~K}$ & $298.15 \mathrm{~K}$ & $303.15 \mathrm{~K}$ & $308.15 \mathrm{~K}$ & $313.15 \mathrm{~K}$ \\
\hline \multicolumn{7}{|c|}{$C_{p}^{\mathrm{a}}, \mathrm{J} \mathrm{K} \mathrm{K}^{-1}$} \\
0 & 4.0160 & 4.0220 & 4.0260 & 4.0300 & 4.0350 \\
0.0022 & 4.0147 & 4.0219 & 4.0257 & 4.0303 & 4.0357 \\
0.0071 & 4.0198 & 4.0265 & 4.0307 & 4.0359 & 4.0424 \\
0.0104 & 4.0294 & 4.0389 & 4.0424 & 4.0478 & 4.0528 \\
0.0125 & 4.0371 & 4.0492 & 4.0528 & 4.0591 & 4.0639 \\
0.0198 & 4.0683 & 4.0806 & 4.08675 & 4.0916 & 4.0958 \\
0.0218 & 4.0773 & 4.0901 & 4.0949 & 4.0998 & 4.1046 \\
0.0249 & 4.0899 & 4.1014 & 4.1086 & 4.1107 & 4.1164 \\
0.0320 & 4.1214 & 4.1294 & 4.1322 & 4.1362 & 4.1386 \\
0.0364 & 4.1322 & 4.1409 & 4.1441 & 4.1484 & 4.1513 \\
\hline
\end{tabular}

${ }^{\text {a }}$ Error of experimental values of $C_{p}$ is $\pm\left(0.002 C_{p}\right) \mathrm{J} \mathrm{K}^{-1} \mathrm{~g}^{-1}$.

built-in Pt100 platinum temperature sensors in combination with Peltier elements ensured the thermostatting of a sample inside the cell with an error of $5 \times 10^{-3} \mathrm{~K}$. The standard error in measuring the density of a given solution did not exceed $0.00001 \mathrm{~g} \mathrm{~cm}^{-3}$.

The specific heat capacity $C_{p}$ of the His-buffer system was measured with a SCAL-1 differential scanning microcalorimeter (Biopribor, Pushchino, Moscow oblast, Russia). The integral sensitivity of the calorimeter's detector was $33.218 \mathrm{nW} / \mathrm{mV}$, the calibration power was $25 \mu \mathrm{W}$, the scan speed was $1 \mathrm{~K} / \mathrm{min}$, and the time constant was $20 \mathrm{~s}$. The device, which was described in detail in [15], was tested against the heat capacity of aqueous solutions of sodium chloride recommended as a reference substance for scanning calorimetry of solutions [16]. The standard error in measuring the specific heat capacity of the investigated solutions was $\pm 7 \times 10^{-3} \mathrm{~J} \mathrm{~K}^{-1} \mathrm{~g}^{-1}$. The specific heat capacities of the investigated solutions were measured at temperatures of $288.15,298.15,303.15,308.15$, and $313.15 \mathrm{~K}$.

Tables 1 and 2 present the experimental data obtained for density $\rho$ and specific heat capacity $C_{p}$ of the studied solutions. As the tables show, densities $\rho$ fall as the temperature rises and grow along with the concentration of the amino acid, while specific heat capacities $C_{p}$ grow along with the temperature and concentration.

\section{RESULTS AND DISCUSSION}

Histidine is a basic amino acid with a heterocyclic polar side chain. Depending on the $\mathrm{pH}$ of a medium, His exists in different ionic states and can form three 


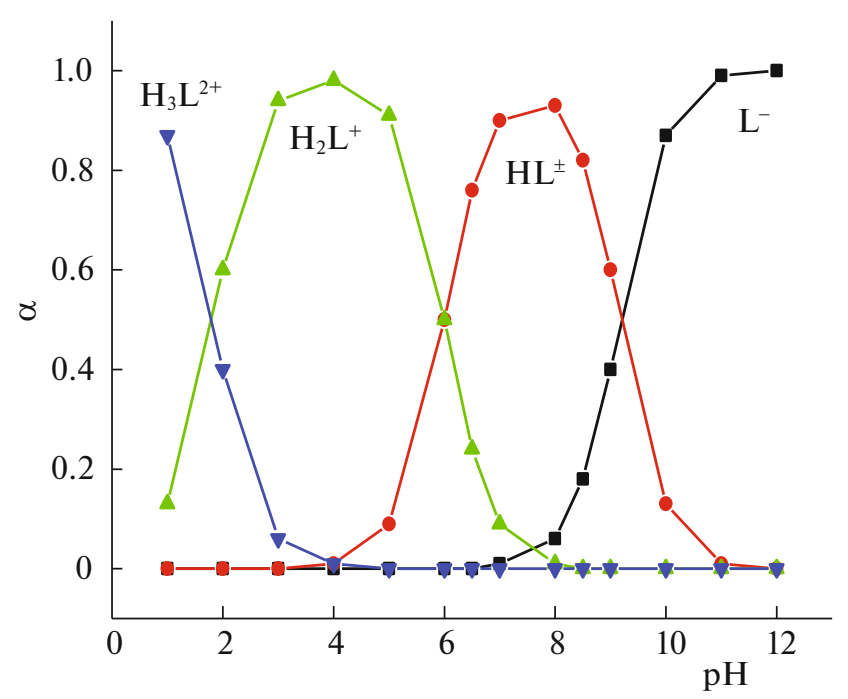

Fig. 1. (Color online) $\mathrm{pH}$ distribution of ionic forms of histidine.

different protonated complexes [17, 18]. The $\mathrm{pH}$ distribution of different forms of the amino acid was constructed using the RRSU software [19] based on a modified Brinkley approach. This $\mathrm{pH}$ distribution shows (Fig. 1) that under the conditions of the chosen buffer medium ( $\mathrm{pH} 7.4)$, His exists primarily in zwitterion form $\left([\mathrm{HL}]^{ \pm}\right)$, and the probability of its cationic form $\left(\left[\mathrm{H}_{2} \mathrm{~L}\right]^{+}\right)$existing is less than $5 \%$.

\section{Volumetric Properties of Solutions}

Apparent molar volume ${ }^{\varphi} V$ of His was calculated from the experimental data on density, using the equation

$$
{ }^{\varphi} V=1000\left(\rho_{0}-\rho\right) /\left(\rho \rho_{0} m\right)+M / \rho,
$$

where $\rho_{0}$ and $\rho$ are the density of the solvent and the solution, respectively, $\mathrm{g} \mathrm{cm}^{-3} ; m$ is the His molality, mol kg-1; and $M$ is the molecular weight of His. The solvent in the binary aqueous solutions His-buffer is the phosphate buffer solution. Figure 2 shows the concentration dependences of the apparent molar volumes of the amino acid at different temperatures.

Concentration dependences ${ }^{\varphi} V=f(m)$ for His in water are described by a linear function [1, 20, 21]; in the buffer solution, they are approximated satisfactorily by a polynomial of the second degree:

$$
{ }^{\varphi} V={ }^{\varphi} V^{\circ}+B_{1} m+B_{2} m^{2}
$$

where $\varphi V^{\circ}$ is the limiting apparent molar volume, which is equal to the partial molar volume at infinite dilution; $B_{1}$ and $B_{2}$ are constant coefficients. Positive values of $\varphi V^{\circ}$ were obtained (Table 3 ). For comparison, Table 3 also presents data on an aqueous solution of L-histidine [20]. As Table 3 shows, the ${ }^{\varphi} V^{\circ}$ values for His in water and the buffer solution grow along

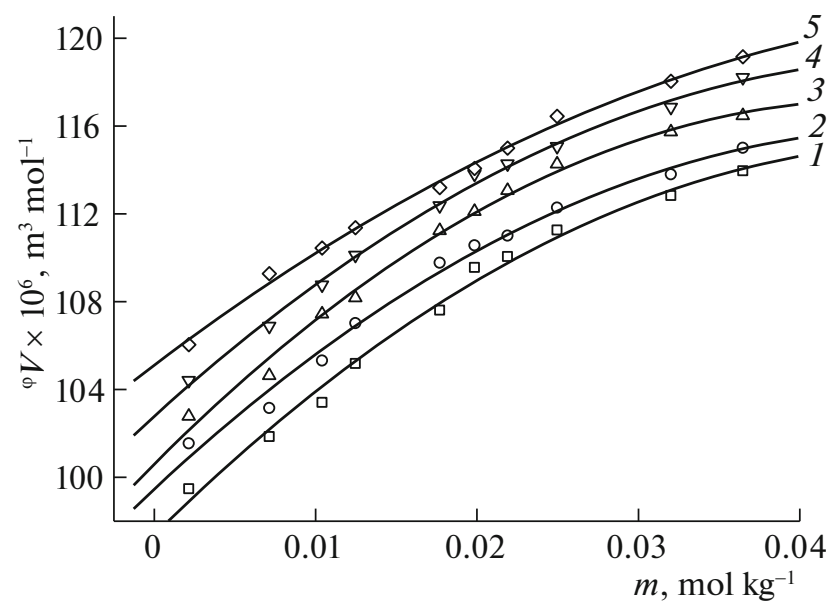

Fig. 2. Concentration dependences of the apparent molar volumes ${ }^{\varphi} V$ of $\mathrm{L}$-histidine in an aqueous buffer solution at temperatures of (1) 288.15, (2) 298.15, (3) 303.15, (4) 308.15 , and (5) $313.15 \mathrm{~K}$.

with temperature, which agrees with the data on other amino acids in aqueous solutions [1, 2, 15, 20-22].

The partial molar volume of His in water is smaller than in the aqueous buffer solution. This suggests that adding the buffer solution enhances the interactions between the dissolved amino acid and the solvent (the

phosphate buffer solution). Change $\Delta_{\mathrm{tr}} V_{\varphi}^{\circ}$ in the partial molar volume in transferring His from water to the buffer solution is calculated as

$$
\left.\left.\Delta_{\text {tr }} V_{\varphi}^{\circ}={ }^{\varphi} V^{\circ} \text { (His-buffer }\right)-{ }^{\varphi} V^{\circ} \text { (His-water }\right) .
$$

The obtained positive values of $\Delta_{\mathrm{tr}} V_{\varphi}^{\circ}$ tend to grow along with temperature (from 1.2 to $2.79 \mathrm{~cm}^{3} \mathrm{~mol}^{-1}$ ). The dissolution of His in water is accompanied by the ionization of its carboxyl and amino groups, the protonation of the imidazole ring in the side chain of the molecule, and the hydration of nonpolar fragments of the ring. Introducing His to the phosphate buffer solution containing ions $\mathrm{Na}^{+}, \mathrm{H}_{2} \mathrm{PO}_{4}^{-}$, and $\mathrm{HPO}_{4}^{2-}$ enhances the electrostatic and hydrophobic interactions. The electrolyte ions interact electrostatically with $\mathrm{NH}_{3}^{+}$and $\mathrm{COO}^{-}$groups of amino acid zwitterions. In addition, the charged imidazole ring, even though the share of them in the buffer solution is low, can coordinate these ions. The dipoles of water molecules are also influenced by the electrostatic forces near cations, anions, and zwitterions. Positive values of $\Delta_{\mathrm{tr}} V_{\varphi}^{\circ}$ mainly characterize the interaction between the buffer electrolyte and the charged sites of the amino acid, weakening their electrostrictive effects and resulting in hydrophobic hydration. These interactions in the buffer solution additionally enhance the weak structure-strengthening tendency of $\mathrm{His}$ in water. Such behavior has also been observed for other 
Table 3. Limiting apparent molar volumes ${ }^{\varphi} V^{\circ}$ of L-histidine (His) and its derivatives with respect to temperature, $\left(\partial^{\varphi} V^{\circ} / \partial T\right)_{p}$, in an aqueous buffer solution and water at different temperatures

\begin{tabular}{c|c|c|c|c}
\hline \multirow{2}{*}{$T, \mathrm{~K}$} & \multicolumn{2}{|c|}{ His-buffer } & \multicolumn{2}{c}{ His-water } \\
\cline { 2 - 5 } & $\begin{array}{c}\varphi V^{\circ} \times 10^{6}, \\
\mathrm{~m}^{3} \mathrm{~mol}^{-1}\end{array}$ & $\begin{array}{c}\left(\partial^{\varphi} V^{\circ} / \partial T\right)_{p} \times 10^{6}[35], \\
\mathrm{m}^{3} \mathrm{~mol}^{-1} \mathrm{~K}^{-1}\end{array}$ & $\begin{array}{c}\varphi V^{\circ} \times 10^{6}[35], \\
\mathrm{m}^{3} \mathrm{~mol}^{-1}\end{array}$ & $\begin{array}{c}\left(\partial^{\varphi} / \partial T\right)_{\mathrm{p}} \times 10^{6 *}, \\
\mathrm{~m}^{3} \mathrm{~mol}^{-1} \mathrm{~K}^{-1}\end{array}$ \\
\hline 288.15 & $97.36 \pm 0.41$ & $0.109 \pm 0.096$ & - & - \\
298.15 & $99.46 \pm 0.39$ & $0.268 \pm 0.090$ & $98.26 \pm 0.10$ & $0.266 \pm 0.091$ \\
303.15 & $100.60 \pm 0.32$ & $0.349 \pm 0.102$ & $99.53 \pm 0.12$ & $0.271 \pm 0.068$ \\
308.15 & $102.77 \pm 0.24$ & $0.427 \pm 0.103$ & $100.93 \pm 0.14$ & $0.275 \pm 0.042$ \\
313.15 & $105.10 \pm 0.23$ & $0.508 \pm 0.106$ & $102.32 \pm 0.14$ & $0.280 \pm 0.043$ \\
\hline
\end{tabular}

$*\left(\partial^{\varphi} V^{\circ} / \partial T\right)_{p}$ was calculated using the equation $\left(\partial^{\varphi} V^{\circ} / \partial T\right)_{p}=\beta+2 T \gamma$, where $\beta$ and $\gamma$ are constants from Eq. (4).

amino acids with polar side radicals in aqueous solutions that contain, e.g., potassium chlorides and nitrates, sodium acetate, propionate, and butyrate [10, $11]$.

The $\Delta_{\mathrm{tr}} V_{\varphi}^{\circ}$ values are sensitive to solvation. According to the Gurney model of hydration shell overlap [23], the volume increases $\left(\Delta_{\mathrm{tr}} V_{\varphi}^{\circ}>0\right)$ if the interactions are due to, e.g., electrostatic forces and hydrogen bonds. The volume shrinks $\left(\Delta_{\mathrm{tr}} V_{\varphi}^{\circ}<0\right)$ if the interactions involve nonpolar groups (hydrophobic forces) [23-27]. The obtained positive changes $\Delta_{\text {tr }} V_{\varphi}^{\circ}$ in the volume indicate that in the His-buffer system, electrostatic interactions and hydrogen bonding dominate ion-hydrophobic interactions (between ions/zwitterions and nonpolar groups of the amino acid) because of the competition between molecular interactions of different types in the studied solutions.

The temperature dependence of partial molar volumes $\varphi V^{\circ}$ of L-histidine in the buffer solution is described by the equation

$$
{ }^{\varphi} V^{\circ}=\alpha+\beta T+\gamma T^{2},
$$

where $\alpha, \beta$, and $\gamma$ are constants; $T$ is temperature. The partial molar volumes of the amino acids grow along with temperature. In addition, the obtained curves are concave (downward) for both aqueous and buffer solutions. Such behavior is typical of aqueous solutions of electrolytes or hydrophilic nonelectrolytes [28]. Table 3 presents the calculated first-order derivatives $\left(\partial^{\varphi} V^{\circ} / \partial T\right)_{p}$. The positive values of the derivatives suggest the release of electrostrictively compressed water from the hydration shells of the amino acid during its dissolution in the buffer solution, which is accompanied by an increase in the volume of the system. It was shown that the $\left(\partial^{\varphi} V^{\circ} / \partial T\right)_{p}$ values grow along with temperature in the His-buffer system, while these values change less in the aqueous solution of the amino acid.

Based on the Hepler equation [28]

$$
\left(\partial C_{p}^{\circ} / \partial P\right)_{T}=-T\left(\partial^{2 \varphi} V^{\circ} / \partial T^{2}\right)_{p}
$$

we can judge the effect the amino acid has on the structure of the solvent. The obtained positive values of the second-order derivative $\left(\partial^{2 \varphi} V^{\circ} / \partial T^{2}\right)_{p}$ for His in both water $\left(0.00097 \mathrm{~cm}^{6} \mathrm{~mol}^{-2} \mathrm{~K}^{-2}\right)$ and the buffer solution $\left(0.0160 \mathrm{~cm}^{6} \mathrm{~mol}^{-2} \mathrm{~K}^{-2}\right)$ testify to the structure-forming ability of the solute.

Figure $3 \mathrm{a}$ illustrates temperature dependences $\varphi V(T)$ of the apparent molar volumes of His in the buffer solution. There is a monotonic sequence of isoconcentration curves ${ }^{\varphi} V(T)$ as the concentration of amino acid grows, showing that no complexes formed between His and components of the buffer solvent.

\section{Heat-Capacity Properties of Solutions}

Apparent molar heat capacity ${ }^{\phi} C_{p}$ of the solute in the buffer solution was determined using the equation

$$
{ }^{\phi} C_{p}=M C_{p}+1000\left(C_{p}-C_{p}^{\circ}\right) / m
$$

where $C_{p}$ and $C_{p}^{\circ}$ are the specific heat capacities of the solution and the solvent, respectively, $\mathrm{J} \mathrm{K}^{-1} \mathrm{~g}^{1} ; m$ is the solute molality, mol kg-1 ; and $M$ is the molar weight of the solute (His), $\mathrm{g} \mathrm{mol}^{-1}$. It is known $[29,30]$ that the heat capacity of solutions is sensitive to features of the interaction between components of solutions. If the solute-solvent and solvent-solvent interactions remain unchanged, the concentration dependences of such heat-capacity properties of the solution are linear. The obtained concentration dependences of the apparent molar heat capacities ${ }^{\phi} C_{p}$ of His in the buffer solution (Fig. 4) are approximated by a polynomial of the third degree throughout the investigated range of parameters $(m, T)$ :

$$
{ }^{\phi} C_{p}(m)={ }^{\phi} C_{p}^{\circ}+A_{1} m+A_{2} m^{2}+A_{3} m^{3} .
$$

Here, ${ }^{\phi} C_{p}^{\circ}$ is the limiting value of the apparent molar heat capacity, which is equal to the partial molar heat capacity at infinite dilution; $A_{1}, A_{2}$, and $A_{3}$ are constant coefficients. The ${ }^{\phi} C_{p}^{\circ}$ values are positive and grow along with temperature from 288.15 to $313.15 \mathrm{~K}$ 

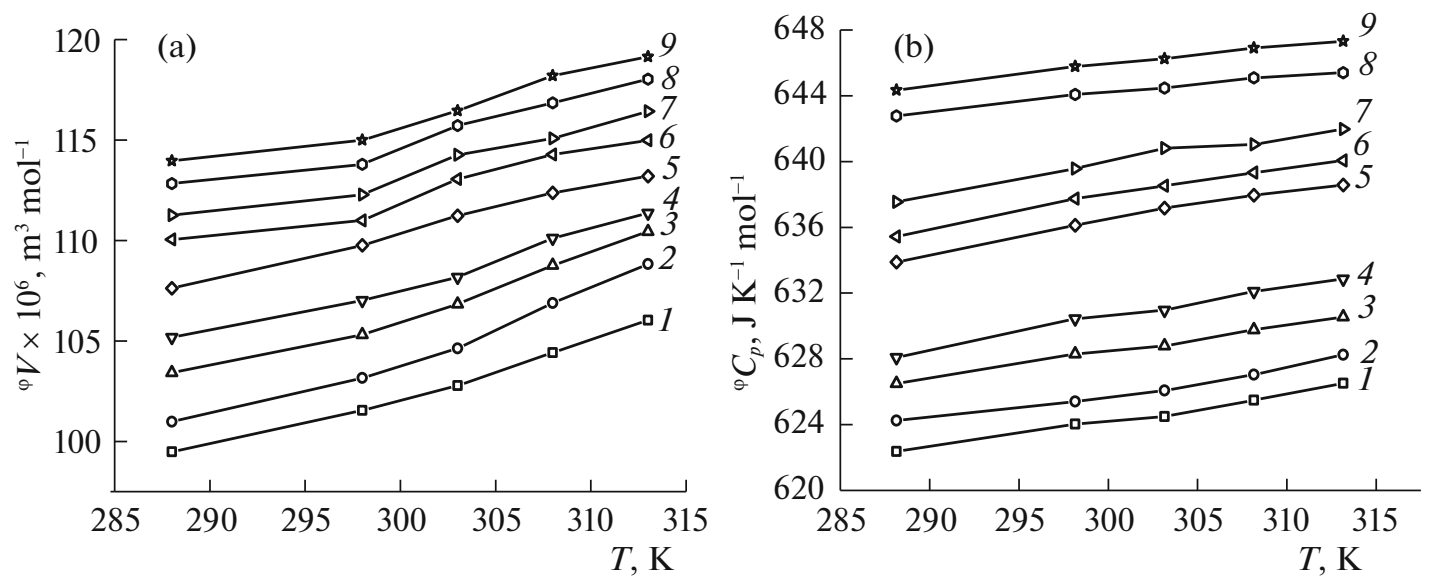

Fig. 3. Temperature dependences of the (a) apparent molar volumes ${ }^{\varphi} V$ and (b) apparent molar heat capacities ${ }^{\phi} C_{p}$ of L-histidine in an aqueous buffer solution at concentrations of (1) $0.0022 m,(2) 0.0071 m,(3) 0.0104 m,(4) 0.0125 m,(5) 0.0198 m,(6) 0.0219 m$, (7) $0.0249 m,(8) 0.0320 m$, and (9) $0.0365 m$.

(Table 4). Such a tendency is also observed in aqueous solutions of L-histidine (Table 4), though the lack of salts $\left(\mathrm{NaH}_{2} \mathrm{PO}_{4}\right.$ and $\left.\mathrm{Na}_{2} \mathrm{HPO}_{4}\right)$ in the water can reduce the electrostatic component of interparticle interaction, resulting in the positive ${ }^{\phi} C_{p}^{\circ}$ values in the water being lower than those in the buffer solution.

A rise in the apparent molar heat capacity of the solute typically reflects an increase in the number of degrees of freedom and the intensity of molecular motions, which destroys the structure of the solvent. A reduction in this heat-capacity property suggest the formation of more ordered structures if there is no effect of other factors, especially dehydration of the molecules of solutes [30-32]. With respect to the dissolution of His in an aqueous buffer solution, we can probably speak about the dominant contribution from the dehydration of molecules to the total heat capacity of the solution.

The partial molar heat capacity of the transfer of His from water to the buffer solution was found as

$$
\left.\Delta_{\mathrm{tr}} C_{p}^{\circ}={ }^{\phi} C_{p}^{\circ} \text { (His-buffer }\right)-{ }^{\phi} C_{p}^{\circ} \text { (His-water). }
$$

The obtained large positive $\Delta_{\mathrm{tr}} C_{p}^{\circ}$ values could mainly be due to a change in the solvation of ionic and hydrophilic groups of the amino acid and components of the buffer solution. Such $\Delta_{\mathrm{tr}} C_{p}^{\circ}$ values usually suggest that aqueous buffer solutions of His are more structured than solutions of the amino acid in pure water $[26,30,33,34]$. According to the Gurney approach $[23,35,36]$, the hydration of His results in some degrees of freedom being lost, making a negative contribution to $\Delta_{\mathrm{tr}} C_{p}^{\circ}$ [37]. The interaction between His and components of the buffer solution through the overlap of the hydration shells of molecules is accompanied by their dehydration, which makes a positive contribution to $\Delta_{\mathrm{tr}} C_{p}^{\circ}[35,38]$. For $\Delta_{\mathrm{tr}} C_{p}^{\circ}$, there is also a positive contribution from the ion-hydrophilic interactions of zwitterionic sites $\left(\mathrm{COO}^{-} / \mathrm{NH}_{3}^{+}\right)$of His with ions of the buffer solution through the overlap of their hydration shells, and a negative contribution from the ion-hydrophobic forces acting between the ions and apolar fragments of the amino acid molecule [24, 29, 38]. We may therefore assume that the contributions from ionic-zwitterionic/hydrophilic interactions to $\Delta_{\mathrm{tr}} C_{p}^{\circ}$ dominate those from interactions of other types in the buffer solution of His.

The temperature dependences of limiting apparent molar heat capacities ${ }^{\phi} C_{p}^{\circ}$ of His in water and the buffer solution are described by polynomials of the second degree (coefficient of correlation $R=0.9987$ ):

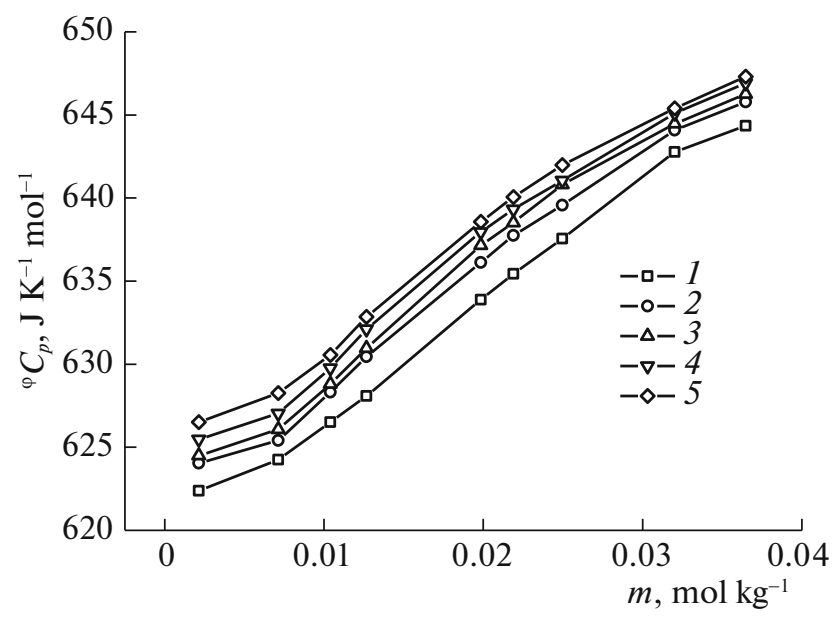

Fig. 4. Concentration dependences of the apparent molar heat capacities ${ }^{\phi} C_{p}$ of L-histidine in an aqueous buffer solution at temperatures of (1) 288.15, (2) 298.15, (3) 303.15 , (4) 308.15 , and (5) $313.15 \mathrm{~K}$. 
Table 4. Limiting apparent molar heat capacities ${ }^{\phi} C_{p}^{\circ}$ of L-histidine (His) and its derivative with respect to temperature, $\left(\partial^{\phi} C_{p}^{\circ} / \partial T\right)_{p}$, in an aqueous buffer solution and water at different temperatures

\begin{tabular}{c|c|c|c|c}
\hline \multirow{2}{*}{$T, \mathrm{~K}$} & \multicolumn{2}{|c|}{ His-buffer } & \multicolumn{2}{c}{ His-water } \\
\cline { 2 - 5 } & $\begin{array}{c}{ }^{\phi} C_{p}^{\circ}, \\
\mathrm{J} \mathrm{K}^{-1} \mathrm{~mol}^{-1}\end{array}$ & $\begin{array}{c}\left(\partial^{\phi} C_{p}^{\circ} / \partial T\right)_{p}, \\
\mathrm{~J} \mathrm{~K}^{-2} \mathrm{~mol}^{-1}\end{array}$ & $\begin{array}{c}{ }^{\phi} C_{p}^{\circ}[45], \\
\mathrm{J} \mathrm{K}^{-1} \mathrm{~mol}^{-1}\end{array}$ & $\begin{array}{c}\left(\partial^{\phi} C_{p}^{\circ} / \partial T\right)_{p}, \\
\mathrm{~J} \mathrm{~K}^{-2} \mathrm{~mol}^{-1}\end{array}$ \\
\hline 288.15 & $621.58 \pm 0.50$ & $0.2004 \pm 0.036$ & $212.20 \pm 0.09$ & $2.3301 \pm 0.006$ \\
298.15 & $623.31 \pm 0.61$ & $0.1522 \pm 0.045$ & $232.90 \pm 0.08$ & $1.9324 \pm 0.008$ \\
303.15 & $623.96 \pm 0.53$ & $0.1281 \pm 0.046$ & - & - \\
308.15 & $624.74 \pm 0.60$ & $0.1040 \pm 0.046$ & - & - \\
313.15 & $625.03 \pm 0.50$ & $0.0799 \pm 0.051$ & $258.10 \pm 0.10$ & $1.3360 \pm 0.010$ \\
328.15 & - & - & $273.21 \pm 0.10$ & $0.7396 \pm 0.015$ \\
\hline
\end{tabular}

$\left(\partial^{\phi} C_{p}^{\circ} / \partial T\right)_{p}$ was calculated using the equation $\left(\partial^{\phi} C_{p}^{\circ} / \partial T\right)_{p}=b_{1}+2 T b_{2}$, where $b_{1}$ and $b_{2}$ are constants from Eq. (9).

$$
{ }^{\phi} C_{p}^{\circ}(T)=a+b_{1} T+b_{2} T^{2},
$$

where $T$ is temperature, $\mathrm{K}$; and $a, b_{1}$, and $b_{2}$ are constants. Table 4 presents the first-order derivatives $\left(\partial^{\phi} C_{p}^{\circ} / \partial T\right)_{p}$. Figure $3 \mathrm{~b}$ shows the temperature dependences of the apparent molar heat capacities ${ }^{\phi} C_{p}(T)$ of His in the buffer solution at different concentrations. It is clear there is no disorder in the arrangement of isoconcentration lines, and the ${ }^{\phi} C_{p}$ values grow along with both the temperature and concentration of the amino acid in the solution.

\section{CONCLUSIONS}

Experimental values of the density and specific heat capacity of buffer solutions containing L-histidine in the 0.00215 to $0.03648 \mathrm{~mol} \mathrm{~kg}^{-1}$ range of concentrations and the $288.15-313.15 \mathrm{~K}$ range of temperatures were determined via densimetry and differential scanning calorimetry. The apparent and partial molar properties $\left({ }^{\varphi} V_{\mathrm{His}},{ }^{\phi} C_{p}\right)$ of L-histidine were found, and the limiting apparent molar properties of the transfer of His from water to the buffer solution were determined. The observed positive values $\left(\Delta_{\mathrm{tr}} V_{\varphi}^{\circ}\right.$, $\Delta_{\mathrm{tr}} C_{p}^{\circ}$ ) of the transfer of His from water to the buffer solution at all of the investigated temperatures are due primarily to hydration and the interaction between hydrated molecules and ions of L-histidine and electrolytes of the buffer solution, respectively, by electrostatic forces and hydrogen bonding.

Parameters $\quad\left(\partial^{\phi} C_{p}^{\circ} / \partial T\right)_{p}, \quad\left(\partial^{\varphi} V^{\circ} / \partial T\right)_{p}, \quad$ and $\left(\partial^{2 \varphi} V^{\circ} / \partial T^{2}\right)_{p}$ of His in the buffer solution and water were found. The observed tendency in the change in $\left(\partial^{\varphi} V^{\circ} / \partial T\right)_{p}$ and $\left(\partial^{2 \varphi} V^{\circ} / \partial T^{2}\right)_{p}$ at different temperatures suggests that L-histidine helps strengthen the structure of the solution. It was shown that compared to an aqueous solution, the structure-forming effects of His are stronger in an aqueous buffer solution.

\section{ACKNOWLEDGMENTS}

Density and specific heat capacity were measured on equipment at the Upper Volga Regional Center for Physicochemical Research, Krestov Institute of Solution Chemistry, Russian Academy of Sciences, Ivanovo, Russia (http://www.isc-ras.ru/ru/struktura/ckp).

\section{REFERENCES}

1. Y. Yasuda, N. Tochio, M. Sakurai, and K. Nitta, J. Chem. Eng. Data 43, 205 (1998).

2. D. Kumar, S. K. Lomesh, and V. Nathan, J. Mol. Liq. 247, 75 (2017).

3. P. L. Privalov, J. Solution Chem. 44, 1141 (2015).

4. Y. Akhtar and S. F. Ibrahim, Arab. J. Chem. 4, 487 (2011).

5. T. S. Banipal, N. Kaur, and P. K. Banipal, J. Chem. Thermodyn. 82, 12 (2015).

6. A. K. Nain, R. Pal, and R. K. Sharma, J. Mol. Liq. 165, 154 (2012).

7. H. Kumar, M. Singla, and R. Jindal, J. Chem. Thermodyn. 70, 190 (2014).

8. M. Taha and M.-J. Lee, J. Chem. Thermodyn. 41, 705 (2009).

9. J. J. Jardine, T. G. Call, B. A. Patterson, M. L. OrigliaLuster, and E. M. Woolley, J. Chem. Thermodyn. 33, 1419 (2001).

10. A. T. Riyazuddeen, Thermochim. Acta 501, 72 (2010).

11. T. S. Banipal, K. Singh, and P. K. Banipal, J. Solution Chem. 36, 1635 (2007).

12. A. L. Hansena and L. E. Kaya, Proc. Natl. Acad. Sci. U. S. A., E1705 (2014). www.pnas.org/cgi/doi/ 10.1073/pnas.1400577111

13. Y. Oya-Ohta, T. Ochi, Y. Komoda, and K. Yamamoto, Mutat. Res. 326, 99 (1995).

14. R. K. Chernova, O. V. Varygina, and N. S. Berezkina, Izv. Sarat. Univ., Nov. Ser., Ser.: Khim. Biol. Ekol. 15 (4), 15 (2015).

15. E. Yu. Tyunina, V. G. Badelin, and I. N. Mezhevoi, J. Solution Chem. 46, 249 (2017). 
16. E. C. W. Clarke and D. N. Glew, J. Phys. Chem. Ref. Data 14, 490 (1985).

17. Y. Miao, T. A. Cross, and R. Fu, J. Magn. Reson. 245, 105 (2014).

18. C. Bretti, R. M. Cigala, O. Giuffre, G. Lando, and S. Sammartano, Fluid Phase Equilib. 459, 51 (2018).

19. V. P. Vasil'ev, V. A. Borodin, and E. V. Kozlovskii, Computers in Calculations in Analytical Chemistry (Vysshaya Shkola, Moscow, 1993) [in Russian].

20. N. Sawheney, M. Kumar, A. K. Sharma, and M. Sharma, J. Chem. Thermodyn. 115, 156 (2017).

21. A. Stefaniu and O. Iulian, J. Solution Chem. 42, 2384 (2013).

22. V. G. Badeline, E. Yu. Tyunina, I. N. Mezhevoi, and G. N. Tarasova, Russ. J. Phys. Chem. A 89, 2229 (2015).

23. R. W. Gurney, Ionic Processes in Solution (McGraw Hill, New York, 1953).

24. F. Franks, Water: A Comprehensive Treatise (Plenum, New York, 1973), Vol. 3.

25. H. Kumar and K. Kaur, J. Chem. Thermodyn. 5, 86 (2012).

26. I. V. Terekhova and O. V. Kulikov, Mendeleev Commun. 3, 1 (2002).
27. L. Lepori and P. Gianni, J. Solution Chem. 29, 405 (2000).

28. L. G. Hepler, Can. J. Chem. 47, 4613 (1969).

29. V. P. Vasil'ev, Thermodynamic Properties of Electrolyte Solutions (Vysshaya Shkola, Moscow, 1982) [in Russian].

30. V. A. Latysheva, Usp. Khim. 42, 1757 (1973).

31. R. A. Marriott, Theses (Univ. of Lethbridge, 1999). https://hdl.handle.net/10133/91.

32. E. Yu. Tyunina, Russ. J. Phys. Chem. A 93, 450 (2019).

33. M. M. H. Bhuiyan, A. W. Hakin, and J. L. Liu, J. Solution Chem. 39, 877 (2010).

34. B. Madan and K. A. Sharp, J. Phys. Chem. B 105, 2256 (2001).

35. P. K. Banipal, T. S. Banipal, J. C. Ahluwalia, and B. S. Lark, J. Chem. Thermodyn. 34, 1825 (2002).

36. R. V. Jasra and J. C. Ahluwalia, J. Solution Chem. 11, 325 (1982).

37. B. Madan and K. A. Sharp, Biophys. J. 81, 1881 (2001).

38. B. S. Lark, P. Patyar, T. S. Banipal, and N. Kishore, J. Chem. Eng. Data 49, 553 (2004).

Translated by V. Glyanchenko 